\title{
DESENVOLVIMENTO DE HABILIDADES DE LEITURA MULTILETRADA NAS AULAS DE GEOGRAFIA: UM RELATO DE EXPERIÊNCIA
}

\section{DEVELOPMENT OF MULTILETERED READING SKILLS IN GEOGRAPHY CLASSES: AN EXPERIENCE REPORT}

\section{DESARROLLO DE HABILIDADES DE LECTURA MULTILETRADA EN CLASES DE GEOGRAFÍA: UN INFORME DE EXPERIENCIA}

\author{
Vinicius Leite da Silva Carvalhaes ${ }^{1}$ \\ https://orcid.org/0000-0002-1217-4732 \\ Maria de Fátima Ramos de Andrade ${ }^{2}$ \\ https://orcid.org/0000-0003-4945-8752 \\ Ana Sílvia Moço Aparício ${ }^{3}$ \\ https://orcid.org/0000-0001-6725-5372
}

\footnotetext{
${ }^{1}$ Universidade Municipal de São Caetano do Sul, São Caetano do Sul, São Paulo - Brasil. E-mail: vlscarvalhaes@gmail.com.

${ }^{2}$ Universidade Municipal de São Caetano do Sul, São Caetano do Sul, São Paulo - Brasil. E-mail: mfrda@uol.com.br.

${ }^{3}$ Universidade Municipal de São Caetano do Sul, São Caetano do Sul, São Paulo - Brasil. E-mail: anaparicio@uol.com.br.
}

\section{Resumo}

Desenvolver atividades que explorem diversos gêneros textuais, na perspectiva dos multiletramentos, tem sido muito valorizado no contexto escolar. Hoje, além de textos escritos, somos obrigados a extrair informação e conhecimento de imagens, gráficos, tabelas, músicas, animações etc., que exigem um preparo diferenciado tanto do professor quanto dos alunos. $\mathrm{O}$ presente artigo tem como objetivo investigar as habilidades de leitura de textos multissemióticos que podem ser desenvolvidas em alunos do ensino médio. Como objetivo específico tem-se a aplicação de uma sequência didática cuja intenção é trabalhar com mímica e desenho a fim de desenvolver habilidades de leitura que sejam necessárias para a resolução de questões-problema dentro da perspectiva dos multiletramentos. Percebe-se que, além de engajamento e dedicação, os alunos envolvidos na atividade desenvolveram habilidades de leitura que não são restritas apenas ao universo do texto escrito.

Palavras-Chave: Multiletramento. Ensino de Geografia. Práticas Pedagógicas. 


\begin{abstract}
Developing activities that explore different textual genres, from the perspective of multiliteracy, has been highly valued in the school context. Today, in addition to written texts, we are obliged to extract information and knowledge from images, graphics, tables, music, animations, etc., which require different preparation from both the teacher and the students. This article aims to investigate the reading skills of multisemiotic texts that can be developed in high school students. As a specific objective, there is the application of a didactic sequence whose intention is to work with mimicry and drawing in order to develop reading skills that are necessary for the resolution of problem questions within the perspective of multiliteracy. It is noticed that in addition to engagement and dedication, students involved in the activity developed reading skills that are not restricted to the universe of written text alone.
\end{abstract}

Keywords: Multiliteracy. Geography Teaching. Pedagogical Practices.

\title{
Resumen
}

El desarrollo de actividades que exploran diferentes géneros textuales, desde la perspectiva de elementos múltiples, ha sido muy valorado en el contexto escolar. Hoy, además de los textos escritos, estamos obligados a extraer información y conocimiento de imágenes, gráficos, tablas, música, animaciones etc., que requieren una preparación diferente tanto del profesor como de los alumnos. Este artículo tiene como objetivo investigar las habilidades de lectura de textos multisemióticos que pueden desarrollarse en estudiantes de la enseñanza secundaria. Como objetivo específico existe la aplicación de una secuencia didáctica cuya intención es trabajar con mimetismo y dibujo para desarrollar las habilidades de lectura que son necesarias para la resolución de preguntas problemáticas dentro de la perspectiva de las herramientas múltiples. Se observa que, además del compromiso y la dedicación, los estudiantes involucrados en la actividad desarrollaron habilidades de lectura que no se limitan solo al universo del texto escrito.

Palabras clave: Multiliteración. Enseñanza de Geografía. Prácticas Pedagógicas.

\section{Introdução}

A partir da ocupação da espécie humana em praticamente todo o Globo percebemos o quanto as paisagens vêm sendo alteradas num ritmo cada vez mais veloz. Pérez Gómez (2015, p. 15), ao discutir as transformações humanas, apontou "três áreas fundamentais da vida social: o âmbito da produção/consumo (economia), o âmbito do poder (político) e o âmbito da experiência cotidiana (sociedade e cultura)". O que houve para que as transformações sociais ganhassem velocidade de aspecto exponencial? Uma das justificativas para tal está vinculada ao surgimento e aprimoramento constante da internet. Aliás, a vida contemporânea está absolutamente interligada a essa nova estrutura.

Ignorar todas as mudanças do século XXI e colocar em prática uma abordagem semelhante às fontes de informação tradicionais (ou anteriores ao advento da internet) resultará 
num imenso erro. A tecnologia da informação não trabalha apenas com textos escritos (que era basicamente a forma hegemônica em que a informação e o conhecimento se apresentavam). Pérez Gómez (2015, p. 20) escreve que:

\footnotetext{
O mundo da tela é muito diferente do mundo da página escrita, requer uma vida intelectual, perceptiva, associativa e reativa muito distinta. Nasce uma nova ética intelectual que define, de forma diferenciada, o que consideramos conhecimento válido, assim como as suas formas de aquisição, distribuição e consumo.
}

A intervenção de um docente é crucial para que o nosso jovem não se "afogue" nessa enxurrada de informações que lhe é bombardeada constantemente. Houve por um instante a errada impressão de que, como acessar conteúdo estava mais fácil, qualquer um poderia transformá-lo em conhecimento (o que já percebemos que não condiz com a realidade). Pelo menos ao que se refere ao contexto formal de educação, nós, professores,

[...] deveríamos nos dar conta de que não é aconselhável apenas fornecer informação aos alunos, temos que ensiná-los como utilizar de forma eficaz essa informação que rodeia e enche as suas vidas, como acessá-la e avaliá-la criticamente, analisá-la, organizá-la, recriá-la e compartilhá-la. (PÉREZ GÓMEZ, 2015, p. 29)

As novas demandas da sociedade contemporânea pedem que os espaços sociais, em especial a escola, acolham os processos comunicacionais atuais e contribuam para a formação de cidadãos que saibam trabalhar com diferentes mídias/mediações. A atualidade pede que levemos em conta a diversidade e a pluralidade de textos e escritas que circulam entre nós.

Sendo assim, o presente artigo tem como objetivo investigar as habilidades de leitura de textos multimodais e multissemióticos que podem ser desenvolvidas em alunos do ensino médio. Como objetivos específicos têm-se a construção e a aplicação de uma sequência didática com alunos que compõem o universo de professor de um dos autores a fim de desenvolver habilidades de leitura que sejam necessárias para a resolução de questões-problema dentro da perspectiva dos multiletramentos. 


\section{$2 \mathrm{O}$ conceito de multiletramento}

O primeiro conjunto de estudiosos que se debruçou sobre essa temática foi intitulado de New London Group ou Grupo de Nova Londres (GNL). Em 1996, esse grupo de pesquisadores de origens estadunidense, britânica e australiana, especialistas em linguística e educação, reuniu-se em New Hampshire, na cidade de Nova Londres, nos EUA para, juntos, cunharem o termo "multiletramentos", descrevendo-o em A pedagogy of multilietracies: designing social futures (Uma pedagogia dos multiletramentos: desenhando futuros sociais).

O GNL propunha que esse debate deveria ser incorporado ao ambiente escolar para que não fosse reforçado apenas um padrão de estrutura do conhecimento. Em outras palavras, observa-se que a escola mantém um único padrão letrado ano após ano. É a escola que homogeneíza os conteúdos e as formas de transmiti-los, ignorando a existência de outras possibilidades. Isso pode ser feito de maneira consciente ou não, porém, independentemente dessa questão, o fato é que essa negligência da diversidade cultural dentro do ambiente escolar acaba por nos colocar em um círculo vicioso: da mesma forma que a escola nos coloca nessa situação, também é o ambiente escolar que pode nos retirar dela (CAZDEN et al., 1996).

Rojo (2008), com base nos estudos do GNL, reforça a ideia de que todas as expressões culturais são passíveis de estruturar conteúdos e formas de compartilhamento de conhecimento. Por ser uma pesquisadora brasileira e conviver com a diversidade e desigualdade sociais presentes aqui no Brasil, ela considera emergente a temática.

O conceito de multiletramento surge justamente a partir da aceitação dessa diversidade cultural. Rojo e Moura (2012, p. 13) o definem da seguinte maneira:

\footnotetext{
Diferentemente do conceito de letramento (múltiplo), que não faz senão apontar para a multiplicidade e variedade das práticas letradas, valorizadas ou não nas sociedades em geral, o conceito de multiletramento - é bom enfatizar - aponta para dois tipos específicos e importantes de multiplicidade presentes em nossas sociedades, principalmente urbanas, na contemporaneidade: a multiplicidade cultural das populações e a multiplicidade semiótica de constituição dos textos por meio dos quais ela se transforma e se comunica.
}

Em outras palavras, não basta variar a maneira de se comunicar, transmitir ou compartilhar conhecimento. Há uma variação do próprio conhecimento mediante a 
caracterização cultural do grupo em questão. Rojo (2012, p. 10) ainda acrescenta às características dos multiletramentos:

[...] eles são interativos; mais que isso, eles são colaborativos; eles fraturam e transgridem as relações de poder estabelecidas, em especial as relações de propriedade (das máquinas, das ferramentas, das ideias, dos textos (verbais ou não)); eles são híbridos, fronteiriços, mestiços (de linguagens, modos, mídias e culturas). Assim sendo, o melhor lugar para eles existirem é "nas nuvens" e a melhor maneira de se apresentarem é na estrutura ou formato de redes (hipertextos, hipermídias).

Talvez a aceitação desse conceito não seja o problema, mas, sim, colocá-lo em prática. Os grupos sociais se impõem uns sobre os outros: esse é o maior desafio. Infelizmente vivemos num coletivo em que certas práticas e conteúdos são mais valorizados do que outros. E é justamente esse cenário que acaba por atrapalhar o avanço dessa nova área de pesquisa.

Moita-Lopes e Rojo (2004) definem textos multissemióticos como sendo os que extrapolam o uso restrito da linguagem escrita alfabética. Cores, imagens, sons, design etc. fazem parte da multissemiose dos textos atuais (o que ganhou muita relevância e popularidade com o advento da tecnologia). Essa diversidade está disponível na tela dos computadores, tablets, smartphones e até nos textos impressos. Assim, o letramento tradicional (da letra) tornase insuficiente para a interpretação de todas as formas de comunicação nas quais estamos inseridos. É de extrema importância investir também nos letramentos visual, auditivo etc.

\section{Multimodalidade: uma variação de gêneros}

Analisando o ambiente escolar do ensino médio, percebe-se uma imensa dificuldade por parte dos alunos em interpretar todo tipo de signo. Os resultados das avaliações de larga escala como o Índice de Desenvolvimento da Educação Básica (IDEB) também confirmam tal realidade, Observando-se uma fragilidade na interpretação de enunciados.

Para que os professores possam contribuir não só para a melhora dos resultados internos da escola, mas também para a das avaliações externas, como o IDEB etc., é muito importante debater o conceito de compreensão por meio do significado de linguagem e língua, os quais auxiliam o processo de compreensão (dentro do âmbito de aprendizagem) a partir de um caminho estabelecido pela Linguística (mais especificamente, os gêneros textuais) e pela Neuropsicologia (VASCONCELOS; DIONÍSIO, 2013). 
Ainda segundo Vasconcelos e Dionísio (2013), a capacidade que os seres humanos têm de transformar suas ideias em signos (o que possibilita uma interação) só é viabilizada pela utilização de um sistema de signos convencionados. Essa capacidade humana nós chamamos de linguagem, entretanto é necessária a utilização de um sistema de signos percebidos pelos sentidos e que extrapole o âmbito linguístico. Segundo Gil (2010, p. 2):

[...] se o ser humano pode conhecer o mundo e nele agir, é graças a um funcionamento coordenado dos recursos cognitivos e às múltiplas conexões que o cérebro tece, não só entre os dois hemisférios, mas também no interior de cada hemisfério, desenhando uma rede complexa, articulada de uma ponta à outra da neuraxe. Inúmeros vínculos são tecidos entre a cognição, a afetividade, a sensitividade e a motricidade.

O conhecimento que construímos é fundamentado na utilização de inúmeros sentidos. Goldberg (2002, p.89) exemplifica isso dizendo que:

[...] podemos evocar a imagem visual da copa verde de uma árvore, o som de suas folhas movidas pelo vento, o aroma de suas flores desabrochadas e a sensação de aspereza da casca em nossos dedos.

Ainda segundo o autor, embora as representações de objetos e eventos tenham "múltiplas modalidades sensoriais", em determinados contextos utilizamos mais um sentido do que o outro. Isso pode ser facilmente provado quando pedimos a descrição de algum objeto ou pessoa. É muito mais comum fazermos uma descrição visual (portanto, física) do que auditiva, olfativa ou motora. Em outras palavras, um objeto primeiramente será descrito no que se refere a forma, tamanho e cor e, só depois, o cheiro, o som emitido e a sua textura seriam analisados. As representações de ações físicas, entretanto, são muito mais motoras do que visuais. Por fim, apenas uma realidade é certa: "o conhecimento que construímos acerca do mundo exterior é multimídia por natureza" (GOLDBERG, 2002, p. 89).

Logo, o uso de diversos tipos de linguagem é observado quando se está inserido em uma sociedade, porém um sistema linguístico adquirido nesse contexto social sempre se sobressai. Quando os seres humanos interagem, é feita uma conexão de culturas que mostra a que grupo étnico e social eles julgam pertencer. E é justamente por meio da língua, uma atividade cognitiva, sociointerativa e sócio-histórica, que nos manifestamos (VASCONCELOS; DIONÍSIO, 2013). 
Ainda segundo Vasconcelos e Dionísio (2013, p. 57):

\begin{abstract}
[...] a linguagem humana pode ser entendida, de forma ampla, como uma herança social, uma prática cultural, que permite aos seres humanos (re)elaborar uma vasta quantidade de conceitos e princípios e a possibilidade de um contínuo crescimento e desenvolvimento cognitivo. Estudos, pesquisas e avaliações neuropsicológicas, em se tratando da linguagem e aprendizagem, trabalham, principalmente, investigando o funcionamento do processo de compreensão. Isto é, o ato de compreender um texto e de expressar o que compreendeu são inter-relacionados e constituem uma condição essencial de uma situação de aprendizagem.
\end{abstract}

Voltando ao cerne deste trabalho, temos a seguinte situação: se queremos interpretar textos multissemióticos, compreender enunciados de um problema ou localizar dados relevantes de uma tabela, é necessário que o conceito de "gêneros multimodais" esteja bem consolidado, porque a variação com qual uma informação se apresenta interfere muito na capacidade de um indivíduo de compreendê-la. Os gêneros são construídos por meio das interações sociais em situações específicas, o que atribui sentido ao nosso meio social. Em outras palavras, o gênero representa uma atividade humana específica que caracteriza determinado grupo social.

Dessa forma, para que um estudante tenha facilidade na interpretação de problemas, é de suma importância que ele tenha tido contato com uma grande variedade de gêneros multimodais. A dificuldade para se atingir o que foi descrito anteriormente é que não são apenas as horas de estudo despendidas para a realização de provas que resultarão na capacidade de reconhecimento dos gêneros, mas também o contexto social em que o estudante está inserido. Ou seja, a interação social e a forma como estamos acostumados a nos comunicar e interagir também exercem influência na capacidade cognitiva.

O grande dilema quando alguém se propõe a entender essas questões é que, além dos fatores externos (como a vida em sociedade), há também os fatores internos (neuropsicológicos) que interferem na forma como os seres humanos aprendem. Aliás, o conceito de aprendizagem necessita ser levado em consideração, uma vez que se querem desenvolver nos alunos as habilidades necessárias para o entendimento de contextos multiletrados.

A capacidade de aprender dos seres humanos depende de inúmeras variáveis e, além disso, é preciso aceitar que cada indivíduo aprende de uma forma e em determinado ritmo. Então, a função dos professores é bastante delicada, uma vez que vários recursos didáticos necessitam ser utilizados a fim de abarcar toda a diversidade discente, o que, talvez, nem seja possível, como argumenta Vasconcelos e Dionísio (2013, p. 51): 


\begin{abstract}
No momento em que um aluno está assistindo a uma aula, na qual o professor está usando recursos semióticos com fins específicos, alguns fatores neuropsicológicos subjacentes e necessários à aprendizagem estão em processo. A adequação do conteúdo, material, metodologia não garante que todos os alunos irão aprender da mesma maneira e que conseguirão entender e armazenar as informações. A codificação, compreensão e retenção dependem da condição neuropsicológica de cada pessoa: isto é, funcionamento neuropsicológico diferente, aprendizagem diferenciada.
\end{abstract}

A partir dessa reflexão, ainda baseando-nos em Vasconcelos e Dionísio (2013, p. 4752), poderíamos afirmar que o objetivo dos professores deveria ser a criação de estratégias eficientes que pudessem atingir o maior número possível de estilos cognitivos, o que possibilitaria experiências efetivas de aprendizagem e resultaria na ampliação de conhecimentos e no desenvolvimento de escalas de funcionamento cognitivo mais eficazes em relação à demanda da vida em sociedade.

"Trazer para o espaço escolar uma diversidade de gêneros textuais em que ocorra uma combinação de recursos semióticos significa promover o desenvolvimento cognitivo de nossos aprendizes" (DIONÍSIO, 2014, p. 41). Essa frase finaliza bem o que foi dito até o momento e prepara o campo acadêmico para se afirmar que multiletrar é mais do que necessário, é obrigatório. Preparar nossos alunos preocupando-nos com a temática multiletrada significa que estamos atentos ao desenvolvimento cognitivo atrelado à atualização das linguagens que permeiam nossas formas de produzir textos. O multiletramento, portanto, deveria aparecer dentro de qualquer disciplina por meio de atividades que propiciem o entendimento de que o nosso alfabeto não é mais formado apenas por letras (DIONÍSIO, 2014). Segundo Umberto Eco e Jean-Claude Carrière (2010, p. 19), "o nosso alfabeto expandiu-se”.

A compreensão textual que queremos que os nossos alunos desenvolvam necessita da perspectiva da multimodalidade. Dionísio (2014, p. 42) faz a seguinte afirmação:

Portanto, é no texto, materialidade dos gêneros, onde os modos (imagem, escrita, som, música, linhas, cores, tamanho, ângulos, entonação, ritmos, efeitos visuais, melodia etc.) são realizados. O que faz que um modo seja multimodal são as combinações com outros modos para criar sentidos. Ou seja, o que faz com que um signo seja multimodal são as escolhas e as possibilidades de arranjos estabelecidas com outros signos que fazemos para criar sentidos, com os mesmos, quais as articulações criadas por eles em suas produções textuais. 
Segundo Jewitt (2009), a multimodalidade é uma abordagem interdisciplinar que compreende que a comunicação e a representação necessitam mais do que a língua. Os estudos sobre esses assuntos estão cada vez mais levando em consideração a influência das novas mídias e tecnologias. As abordagens multimodais estão propondo conceitos, métodos e perspectivas que mesclem aspectos visuais, auditivos, corporificados e espaciais da interação e dos ambientes, bem como da relação entre eles.

Jewitt (2009) divide a multimodalidade em três pressupostos teóricos. Primeiro, a multimodalidade assume que a comunicação sempre está baseada na multiplicidade de modos que contribuem para um mesmo significado. Existe a crença de que um repertório complexo de recursos para a geração de sentidos é usado pelos indivíduos - visuais, falados, gestuais, escritos. Em segundo lugar, a multimodalidade entende que esses recursos descritos anteriormente são socialmente modelados pelo tempo para se tornarem geradores de sentido para cada grupo social específico. Por fim, a multimodalidade pressupõe a utilização desses sentidos mediante os interesses individuais dos seres humanos no que se refere ao objetivo pessoal que cada um pode ter para expressar alguma informação.

Pode-se afirmar, portanto, que os nossos hábitos de leitura foram alterados e estão sendo reelaborados constantemente. Por essa razão, toda a estrutura da educação formal também precisa se reorganizar. Materiais didáticos e estratégias do professor (bem como sistemas de avaliação) precisam acompanhar essas transformações. Conclui-se que o processamento cognitivo das informações trabalhadas na educação formal necessita que o aprendiz se torne multiletrado visualmente em cada disciplina. "Conhecimento científico requer, portanto, multiletramentos" (DIONÍSIO, 2014, p. 66).

\section{Atividade com mímica e desenho}

Pensando em explorar a linguagem corporal e artística dos alunos envolvidos na pesquisa, fizemos uma proposta de atividade que tinha como objetivo trabalhar conceitos geográficos muito importantes e que são executados no ensino médio. A ideia era exercitar a capacidade de se expressar por meio de outras linguagens que não a do texto escrito, sendo necessário, portanto, usar a criatividade e outras formas de linguagem.

Os alunos foram divididos em grupos (de quatro a cinco integrantes) e um sorteio a partir de assuntos pré-selecionados foi realizado para que cada grupo soubesse o tema de sua 
tarefa. Com a temática definida, os alunos deveriam pensar em uma mímica e trazer um desenho para fazer que os demais integrantes da sala adivinhassem o assunto que estava sendo trabalhado. Para organizar as apresentações, também foi sorteada uma ordem segundo os dias da semana em que os alunos têm aulas de Geografia. Nesse sentido, cada grupo tinha condições de pensar previamente na mímica que seria interpretada, bem como já trariam para o dia selecionado o desenho pronto.

Para a apresentação da proposta da atividade, a formação dos grupos e o sorteio de temas e dia de apresentação foram utilizadas duas aulas. Também houve tempo para que os grupos começassem a discutir suas ideias a partir do tema que haviam recebido. Toda a confecção do desenho, bem como do ensaio das mímicas, foi feita em casa ou na própria escola em momentos definidos pelos próprios estudantes.

Vale ressaltar que todos os temas disponibilizados para os alunos já haviam sido trabalhados previamente em sala de aula, portanto todos os alunos espectadores, em tese, tinham conhecimento a respeito do assunto da mímica/desenho que seriam apresentado.

Cada grupo deveria trazer o desenho pronto para o dia da sua apresentação, entretanto o mesmo só seria mostrado para os demais colegas depois da realização da mímica. Além de propiciar um momento de maior desafio (haja vista que a expressão corporal exige mais criatividade para se fazer entender do que os desenhos), a intenção era proporcionar um momento prazeroso e divertido tanto para quem estava fazendo a mímica quanto para quem deveria decifrá-la. Mesmo que os alunos já tivessem adivinhado o tema a partir do teatro realizado, o desenho era apresentado e os integrantes do grupo explicavam suas ideias e os motivos que justificavam os elementos escolhidos para o desenho.

É importante salientar que o tempo total de duração dessa atividade foi de quase dois meses, pois as apresentações foram escalonadas ao longo desse período a fim de permitir a aplicação de outras estratégias didáticas que fossem auxiliando os alunos conforme ocorriam as apresentações. Em outras palavras, algumas dicas e sugestões eram emitidas pelo professor a fim de que os futuros grupos conseguissem colocar em prática ações que permitissem o desenvolvimento das habilidades de interesse. Como será explicitado de forma específica no item a seguir, ao término de cada apresentação foi realizado um debate com todos os alunos para esclarecimento de dúvidas e realização de comentários livres a respeito da experiência de assistir e apresentar a mímica/desenho. 


\section{Resultado da atividade: desenhos realizados}

A seguir serão apresentados alguns exemplos de desenhos feitos pelos próprios alunos, bem como a transcrição da justificativa que os mesmos forneceram ao explicá-los para mim e para os demais colegas. A fim de não perder qualquer detalhe dessa explicação, fiz gravações dos alunos para posterior transcrição.

Tigres Asiáticos: esse grupo de países (representado por Cingapura, Taiwan, Hong Kong e Coreia do Sul) apresentou um crescimento econômico extremamente elevado num curto espaço de tempo. Realizaram investimentos na área de educação e indústria para alcançarem tal patamar.

O grupo de alunos que ficou responsável por esse tema fez uma mímica que tentava imitar um tigre com movimentos das mãos e da boca, enquanto os outros integrantes "puxavam" os olhos na tentativa de mostrar que se tratava de uma região oriental. A classe rapidamente acertou. Frases como "fazendo o tigre ficou muito fácil" foram proferidas.

Figura 1 - Desenho sobre os "Tigres Asiáticos".

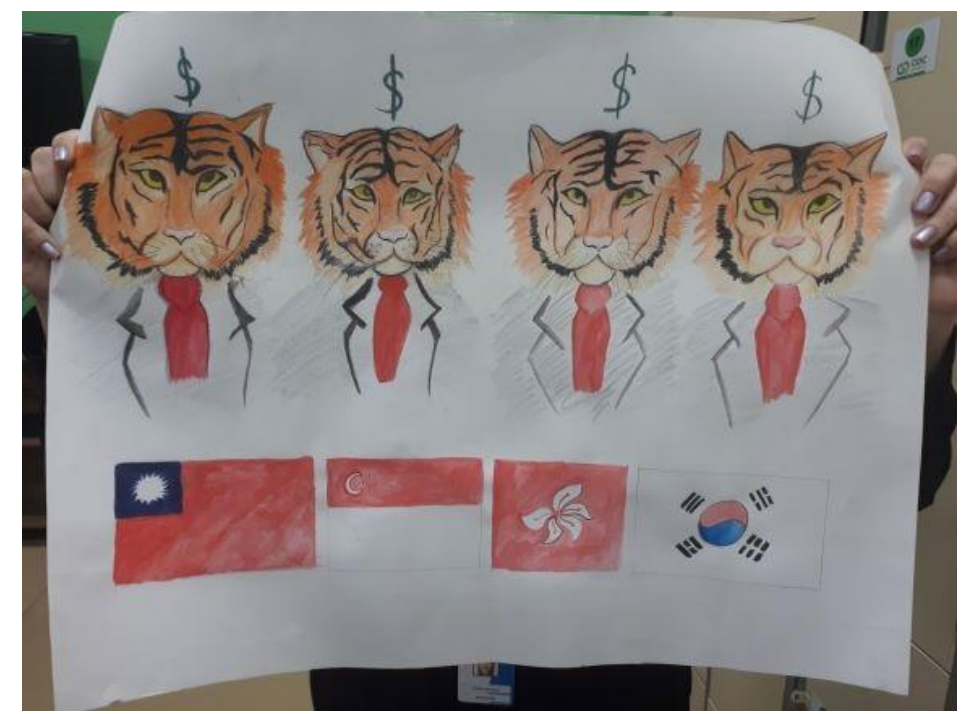

Fonte: O autor (2019).

Já a explicação do desenho foi a seguinte: os alunos disseram que desenharam o tigre (e que sabiam que assim ficaria muito fácil), mas que tentaram explorar outros detalhes -como o símbolo de dinheiro (\$) para representar a riqueza dos países, bem como suas bandeiras. Além 
disso, os tigres foram desenhados de terno e gravata (na tentativa de mostrar que eram empresários).

Continentalidade e Maritimidade: esses são fatores climáticos que influenciam as características dos elementos do clima (como temperatura e umidade). Com latitudes e altitudes parecidas, regiões próximas ao mar tendem a não apresentar extremos de temperatura, enquanto áreas mais ao interior exibem temperaturas mais elevadas no verão e menores no inverno.

Esse grupo disse que teve muita dificuldade em pensar na mímica, pois, a princípio, não sabia como representar a palavra continente (fazendo uma alusão à continentalidade). Eles disseram, então, que pensaram no conceito da palavra. $\mathrm{O}$ grupo representou as seguintes situações: duas pessoas demonstrando estarem com calor; uma estaria fingindo beber água de coco e tomando sol (abanando-se devagar), enquanto a outra estaria num ponto de ônibus impaciente passando muito calor (abanando-se com mais força). A ideia era mostrar que o calor de um lugar era mais intenso do que do outro. A classe demorou um pouco para adivinhar, mas conseguiu chegar à resposta correta.

Figura 2 - Desenho sobre "Continentalidade e Maritimidade".

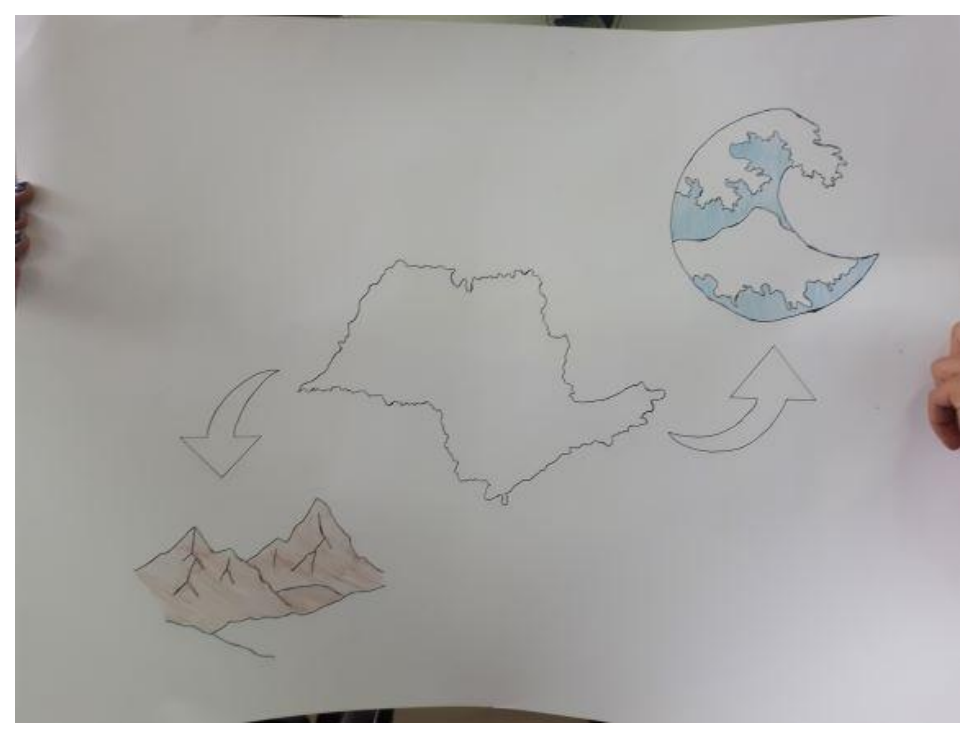

Fonte: O autor (2019).

A justificativa do desenho foi no sentido de que condições climáticas distintas poderiam ser encontradas numa mesma área (nesse caso, o estado de São Paulo). Para diferenciar o local, 
as setas foram desenhadas para representar uma área litorânea (onda e azul da água) e o continente (montanhas e cor marrom).

BREXIT: A saída do Reino Unido da União Europeia (intitulado de BREXIT) se transformou num dos assuntos geopolíticos mais polêmicos dos últimos anos. A política protecionista e isolacionista dos britânicos vai de encontro a uma ideia integralizadora e globalizada do restante da Europa. Diante desse impasse, muitas manifestações populares estão sendo feitas naquele país a fim de que uma saída inteligente seja adotada.

A mímica do grupo consistiu na simulação de uma reunião: uma pessoa fingindo estar com um papel na mão mostrava para outras duas pessoas algo escrito. Uma delas estaria tomando uma bebida quente e demonstrava estar muito contrariada. A outra aparentava ser mais condescendente e aceitava o que estava sendo mostrado. A classe rapidamente acertou com o seguinte argumento: "tomando chá e com essa cara de contrariado só poderia ser o Reino Unido, né!?”.

Figura 3 - Desenho sobre o "BREXIT".

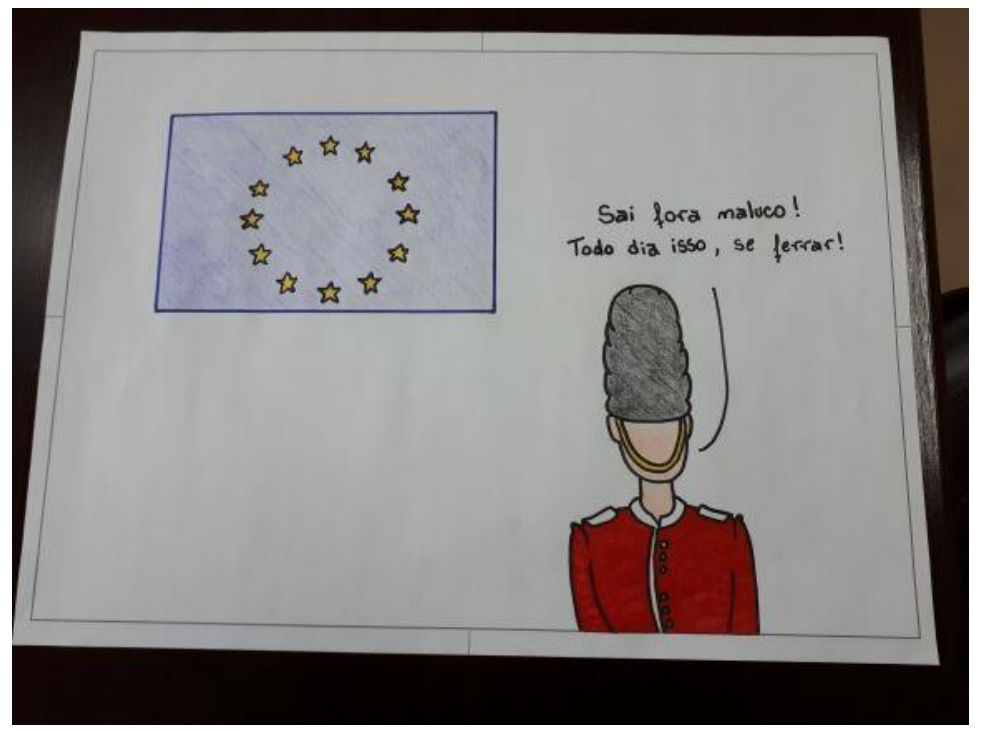

Fonte: O autor (2019).

O desenho quis representar a bandeira da União Europeia e um guarda típico londrino com uma fala de repulsa (que, segundo o grupo, foi adaptada de um meme famoso da internet).

Clima Mediterrâneo: esse tipo de clima se diferencia de todos os outros por apresentar as maiores taxas de precipitação (chuva) no período do inverno (quando geralmente é no verão 
que se observa a maior quantidade de chuva devido às altas temperaturas que contribuem para a evaporação de água). Isso acontece pela dinâmica de circulação de massas de ar em regiões próximas a desertos (como é o caso do Mar Mediterrâneo, próximo ao Deserto do Saara).

O grupo montou uma mímica tentando representar um italiano (que gesticulava muito) e um egípcio (que fazia danças típicas de seu país). Os demais integrantes do grupo representavam o sol e a chuva. Quando o sol estava em cena, a chuva não se aproximava (o que só ocorria quando o sol se distanciava). A justificativa dada por eles foi de que, quando era verão (sol intenso), a chuva era escassa; já no inverno (sol reduzido), a precipitação era maior.

Figura 4 - Desenho sobre o "Clima Mediterrâneo".

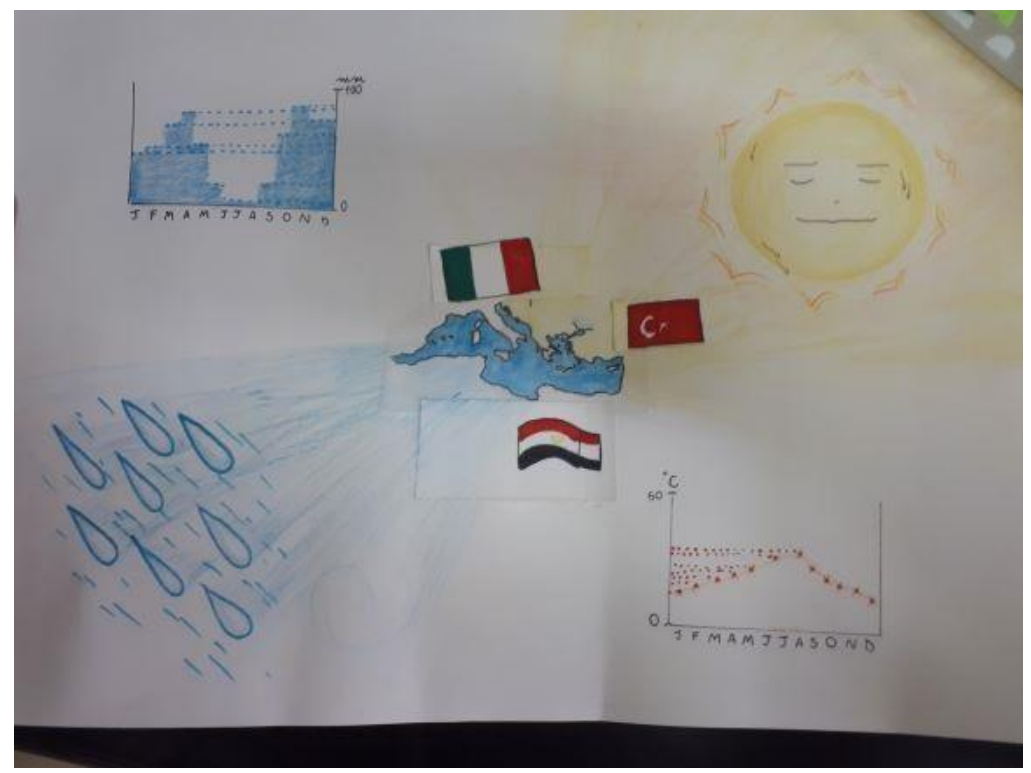

Fonte: O autor (2019).

O desenho do grupo representou dois climogramas (gráficos que apresentam os índices de precipitação e temperatura de um determinado local), além de mostrar o Mar Mediterrâneo com alguns países que são banhados por ele (representados por suas bandeiras: Itália, Turquia e Egito). Por fim, também foram desenhados o sol e a chuva (que, segundo o grupo, foram colocados em lados oposto da cartolina para representar que os dois nunca estão acontecendo ao mesmo tempo). 
Primavera Árabe: o movimento chamado de "Primavera Árabe" representou a revolta popular de alguns países do norte da África e do Oriente Médio contra os governos ditatoriais que dominavam essas regiões.

A mímica do grupo foi composta por pessoas que simulavam uma manifestação contra um indivíduo (que, por sua vez, mandava alguém reprimir a confusão com muita violência). A sala não teve dificuldade em acertar, justificando que o grupo representou muito bem a resistência dos governos árabes contra as manifestações pró-liberdade.

Figura 5 - Desenho sobre a "Primavera Árabe".

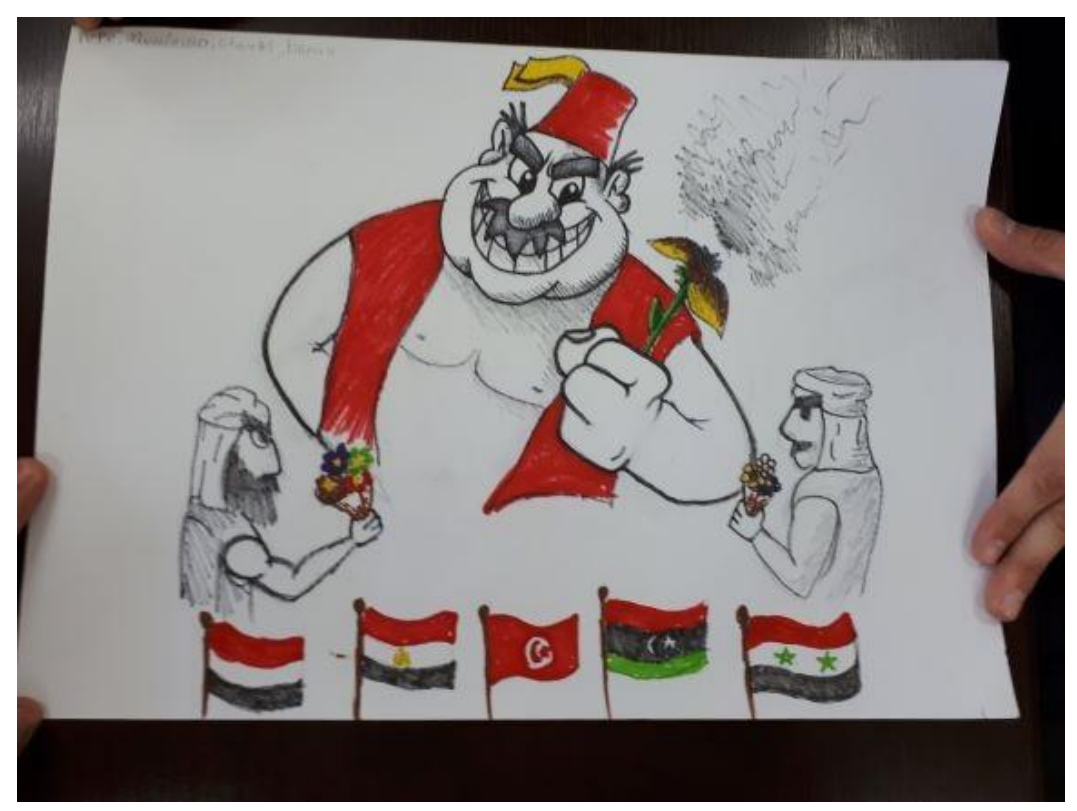

Fonte: o autor (2019).

A justificativa desse grupo para o desenho foi uma das mais detalhadas. Os itens foram justificados da seguinte forma: as bandeiras representavam os países envolvidos no conflito; os personagens desenhados, os árabes (inclusive o "gênio" é uma alusão a uma grande rede de restaurantes que vende comida típica dessa região do planeta); as flores nas mãos dos personagens caracterizavam a primavera (que foi escolhida para nomear o conflito por ser um período de mudança e renovação); e a flor queimando simbolizava que os atos foram muito violentos. A classe elogiou muito o desenho do grupo, bem como a sua explicação.

Movimento Separatista da Catalunha: a região da Catalunha é a mais rica da Espanha e há muito tempo busca tornar-se independente do governo de Madrid por achar que o seu 
crescimento econômico poderia ser ainda melhor caso se tornasse um país autônomo, além de alguns aspectos culturais também a diferenciarem do restante do território espanhol.

A mímica mostrava um grupo de torcedores de futebol assistindo a uma partida. De repente, uma das pessoas se revoltava com o grupo e se afastava. Na sequência, policiais tentavam, à força, fazê-lo torcer novamente com os demais espectadores da partida de futebol. A classe acertou e justificou da seguinte forma: "partida de futebol e manifestação só podia ser em Barcelona"; "o grupo foi muito inteligente em representar uma partida de futebol, pois os times são usados para acirrar ainda mais a rivalidade entre as pessoas”.

Figura 6 - Desenho sobre o "Movimento Separatista da Catalunha".

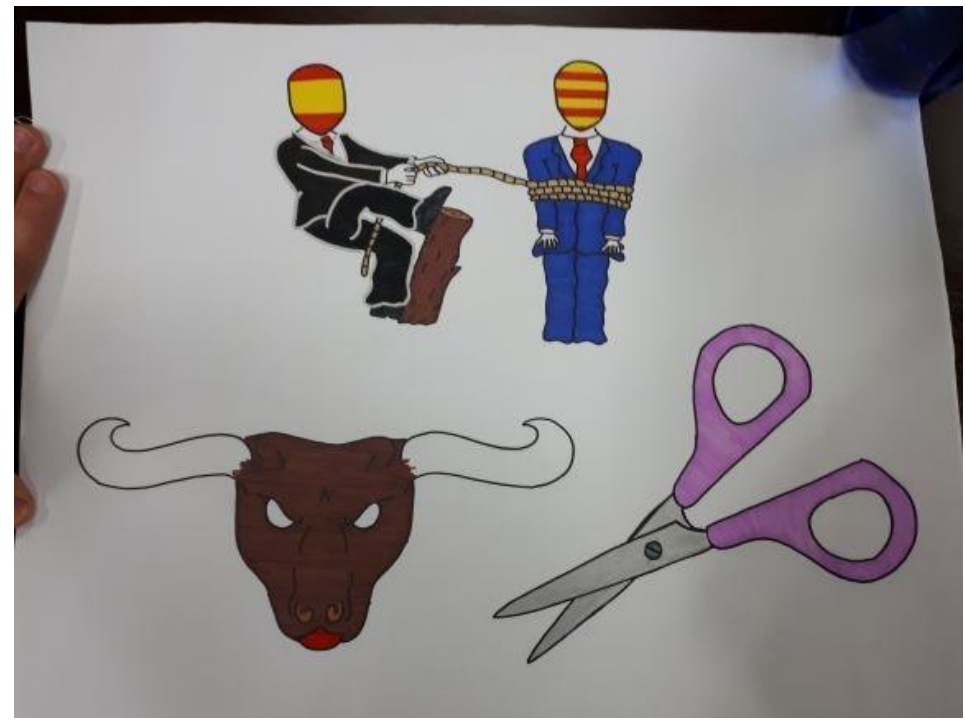

Fonte: O autor (2019).

O grupo explicou que quis representar, em seu desenho, alguém que estaria sendo controlado e impedido de ir embora. A tesoura simbolizava a tentativa dessa pessoa de "cortar" essa ligação. Por fim, o touro era uma alusão às touradas espanholas (manifestação cultural típica do país).

Essa atividade foi muito bem aceita pelos alunos desde o momento da proposta. Foi explicado que não seria atribuída uma nota (o que a princípio nos deixou receosos quanto à dedicação que eles desprenderiam para realizá-la). Felizmente nós estávamos enganados, pois todos se dedicaram muito à realização das duas etapas (mímica e desenho). Após o término de todas as apresentações, fizemos uma roda de conversa para que os alunos fizessem comentários 
a respeito da atividade (impressões, críticas ou sugestões). Eles disseram que gostaram de ter de pensar no roteiro da mímica, nas roupas e acessórios que usariam (uma vez que não seria permitido falar). Muitos disseram que consideraram divertido ver os colegas fazendo as mímicas, o que lhes trouxe prazer e motivação em pensar na sua própria interpretação.

\section{Considerações finais}

Ao aplicar a atividade e, principalmente, quando discutíamos os resultados obtidos, percebemos o quanto a aprendizagem torna-se eficiente quando consideramos, dentro no nosso planejamento escolar, o universo dos alunos. O engajamento que eles apresentaram na realização das tarefas foi algo que nos chamou muito a atenção. As atividades foram realizadas com um empenho visivelmente maior, e o interesse, não só em desenvolver o seu trabalho, mas também em prestar a atenção no trabalho dos demais colegas, foi algo que nos deixou extremamente satisfeitos.

No que se refere à ciência geográfica, Straforini (2018) defende os seguintes conteúdos estruturantes: escala, espaço e tempo. Nós, professores, muitas vezes queremos desenvolver em nossos alunos determinadas habilidades sem utilizar o recurso adequado. É claro que em educação não existe receita infalível, porém, quando variamos o gênero linguístico para atender a cada um desses eixos estruturantes, percebemos como os alunos conseguem compreender e apreender os conhecimentos trabalhados de forma eficaz.

Os itens anteriores permitem-nos perceber que a produção de textos é de extrema importância na apreensão efetiva de uma habilidade multiletrada. O manuseio, a identificação, a análise etc. são, sim, fundamentais, mas a produção é indispensável. 
Figura 7 - Mapa dos Multiletramentos.

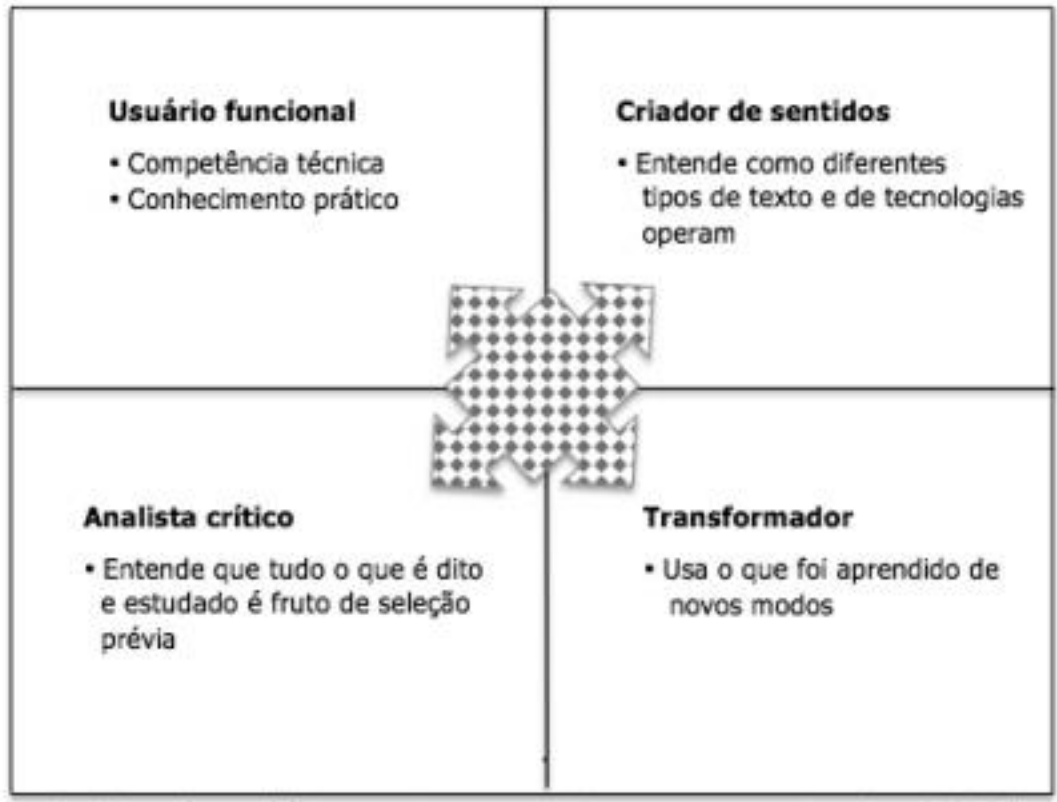

Fonte: COPE, B.; KALANTZIS, M., 2012.

Como pode ser observado no quadro anterior - proposto por Cope e Kalantzis (2006 [2000]), presente no trabalho de Rojo e Moura (2012) -, o conhecimento prévio, a competência técnica, o entendimento do funcionamento dos textos e aplicação/produção dentro de outros contextos contribuem para o desenvolvimento de habilidades multiletradas.

\section{Referências}

CAZDEN, C. et al. A pedagogy of Multilietracies: Designing Social Futures. Harvard Educational Review; Spring 1996.

COPE, B.; KALANTZIS, M. (ed.) Multiliteracies - Literacy learning and the design of social futures. Nova York: Routledge, 2006[2000].

ECO, U.; CARRIÈRE, J. C. Não contem com o fim do livro. Rio de Janeiro: Record, 2010.

GIL, R. Elementos para uma propedêutica da neuropsicologia. In: Neuropsicologia. São Paulo: Santos, 2010, p. 1-20

GOLDBERG, E. O cérebro executivo: lobos frontais e a mente civilizada. Rio de Janeiro: Imago, 2002

JEWITT, C. (ed.) The Routledge Handbook of Multimodal Analysis. New York, Routledge Press, 2009. 
MOITA-LOPES, L. P.; ROJO, R. H. R. Linguagens, Códigos e suas Tecnologias, 2004. In: Brasil/MEC/SEB/DPEM. Orientações Curriculares de Ensino Médio. Brasília, DF: MEC/SEB/DPEM. p. 14-56.

PÉREZ GÓMEZ, Á. I. Educação na era digital: a escola educativa. Porto Alegre: Penso, 2015.

ROJO, R. H. R. O letramento escolar e os textos da divulgação científica - A apropriação dos gêneros de discurso na escola. Linguagem em (Dis)curso, v. 8, n. 3, p. 581-612, set./dez. 2008.

ROJO, R. H. R.; MOURA, E. Multiletramentos na escola. São Paulo: Parábola Editorial, 2012.

ROJO, R. H. R. Pedagogia dos Multiletramentos: Diversidade cultural e de linguagens na escola, 2012.

STRAFORINI, R. O ensino de Geografia como prática espacial de significação. Estud. av., São Paulo, v. 32, n. 93, p. 175-195, Aug. 2018. Disponível em:

http://www.scielo.br/scielo.php?script=sci_arttext\&pid=S0103-

$40142018000200175 \& \operatorname{lng}=e n \& n r m=i s o$. Acesso em: 2 set. 2019.

VASCONCELOS, L. J. de; DIONÍSIO, A. P. Multimodalidade, capacidade de aprendizagem e leitura. In: BUNZEN, C.; MENDONÇA, M. (org.). Múltiplas Linguagens para o Ensino Médio. São Paulo: Parábola Editorial, 2013. p. 43-67.

Recebido em: 15/03/2020

Aprovado em: 13/10/2020

Publicado em: 15/03/2021 